\section{DUNDEE WILL SPEARHEAD CLEFT RESEARCH}

The University of Dundee Dental School is set to spearhead a cutting-edge European initiative on research into craniofacial abnormalities - such as cleft palate - and associated health inequalities in Europe.

Professor Peter Mossey, Associate Dean for Research in the Dental School, has received a European Science Foundation (ESF) grant of approximately $€ 450,000$ for the ESF Network for Orofacial Clefts Research, Prevention and Treatment. According to Professor Mossey, the research programme builds on a previous multi-million Euro and multi-centre collaborative research initiative, EUROCRAN (European collaboration on craniofacial anomalies) which has yielded new insights into genetic and environmental factors that contribute to the cause of orofacial clefts.

Approximately one in 700 live births is affected by a cleft lip and/or palate, with prevalence varying according to geography and ethnicity. In Scotland the birth prevalence of cleft palate is among the highest recorded, along with Finland and Canada; it is lowest in Africa and parts of Latin America. The highest recorded rates of cleft lip are in Asia and parts of Latin America; the lowest in Africa and Southern Europe.

\title{
KING'S IS FIRST CENTRE OF EXCELLENCE
}

King's College Hospital - Dental has been named the UK's first Healthcare Centre of Excellence by GS1 UK, the independent not-for-profit supply chain standards and solutions organisation. The award was granted in recognition of patient improvements achieved by implementing a bar coded 'track-and-trace' system.

Installed by GS1 UK solution provider Meditrax, King's College Hospital Dental now has much more visibility over 16,000 surgical instruments it uses every week. By using a unique identification code for some pieces of equipment, staff are able to locate items quickly and easily. With some specialist surgical tools costing hundreds of pounds to replace each time they are misplaced, it has also helped reduce costs significantly.

The Meditrax system also provides a traceable $\log$ of the sterilisation process, considerably speeding up the decontamination process. It also enhances patient safety by ensuring contaminated instruments are not reused or can be recalled if necessary.

Roger Lamb, Healthcare Manager, GS1 UK, said: 'We hope this will be a catalyst for change for more hospitals to adopt the innovative application of GS1 standards and are tremendously pleased to be able to award Centre of Excellence status to King's College Hospital Dental.'

\section{DIARY}

\section{JUNE}

BACD Bristol Study Club: Realistic, Fast, Fixed Cosmetic Orthodontics for GDPs

Date: 30 June 2011

Location: Bristol

Email:suzy@bacd.com

www.bacd.com

\section{JULY}

BDA Seminar: Occlusion

in everyday dentistry

Date: 1 July 2011

Venue: Park Plaza, Leeds

Email: peter.cowie@bda.org

Telephone: 02075634578

www.bda.org/events

\section{BACD/BDTA Roadshow}

Date: 12 July 2011

Location: Birmingham

Email:suzy@bacd.com

Telephone: 02082418526

Training essentials: Achieving high standards in infection control

Date: 15 July 2011

Venue: BDA, 64 Wimpole Street, London

Email: peter.cowie@bda.org

Telephone: 02075634578

www.bda.org/events

\section{BOOK NOW!}

Teach the Trainers course

Teaches participants how to run the one-day course Writing a journal article and getting it published

Date: 7-9 September 2011

Email: tim@timalbert.co.uk

\section{SHARP DROP IN REFERRALS TO NATIONAL CLINICAL ASSESSMENT SERVICE}

Statistics recently published show a sharp drop in the number of dentists being referred to the National Clinical Assessment Service (NCAS), prompting fears that performance concerns within the profession may be going unnoticed by local managers.

The figures, contained within the 2010/11 Casework Activity Report, show that during the 12-month period to March 2011, there was a reduction of a third in the number of dentists referred to NCAS. Until 2010-2011, there was a steady year on year growth in dentist referrals to NCAS; in 2009-2010, about one dentist in 250 was referred.

NCAS is calling on the NHS to ensure that performance concerns amongst dentists are picked up and acted on as soon as possible to ensure patient care is not compromised.

'We know that most dentists work extremely hard to give an excellent service to their patients, but we also know that there is a small but consistent group who get into difficulty, com- mented Professor Alastair Scotland, Director of NCAS.

'Managing dental services at a time of great change in the NHS makes it much harder for local managers to identify performance concerns at an early stage,' said Dr Janine Brooks, Associate Director of Dentistry at NCAS. 'I don't believe the performance of dentists has suddenly got better. I think it is more likely to be that managers do not have time to effectively observe performancerelated issues.' 